\title{
Effect of Carbon Content on Machinability of Steel in Gear Cutting
}

\author{
Toshiharu AISO ${ }^{1) *}$ and Takashi MATSUMURA ${ }^{2 l}$
}

1) Steel Research Laboratories, Nippon Steel Corporation, 20-1 Shintomi, Futtsu City, Chiba, $293-8511$ Japan.

2) Department of Mechanical Engineering, Tokyo Denki University, 5 Senjyu Asahi-cho, Adachi-ku, Tokyo, $120-8551$ Japan.

(Received on June 3, 2020; accepted on July 14, 2020; originally published in Tetsu-to-Hagané, Vol. 106, 2020, No. 2, pp. 121-131)

\begin{abstract}
Machinability of steels containing different carbon contents is evaluated in cutting with a fly tool of TiAIN coated high speed steel, as performed in gear cutting. In order to investigate the effect of carbon content on the cutting process, $0.2,0.4$ and 0.6 mass $\%$ C steels are prepared with controlling nearly the same hardness. The cutting tests are conducted to measure the cutting forces, observe the chip formations and analyze the damage on the rake and flank faces of the tools. The machinability of the tested steels is compared each other in terms of the cutting model in the cutting force simulation. The orthogonal cutting data are identified to minimize the discrepancies between the measured and the simulated forces. The shear stress on the shear plane becomes large at high carbon contents, and thus the cutting force increases with the carbon content. On the rake face of the tool, substrate softening and cracking in the coated thin layer occur in a certain cutting length. In cutting of the 0.6 mass \% C steel, the cracks initiate rapidly in the coated thin layer on the rake face due to large cutting forces and cutting heat. Small flank wear is observed in the cutting of 0.2 and 0.4 mass $\%$ C steels, while in the 0.6 mass $\%$ C steel thermal wear with adhesion is promoted at high cutting temperatures.
\end{abstract}

KEY WORDS: gear; cutting; fly tool; machinability; steel; carbon; simulation.

\section{Introduction}

Low alloy steels for machine structural use with carbon contents at approximately 0.2 mass $\%$ (hereinafter referred to as\%), e.g., JIS SCM420, are widely used as materials for gears in several industries such as automobile and construction. Gear productions of steels are conducted mainly in hot forging, machining, and case hardening. Reduction of $\mathrm{CO}_{2}$ emissions and energy consumption has recently been emphasized to protect the green environment. In terms of environmental impact, therefore, some issues have been discussed to reduce the carburizing time and replace the carburizing process with induction hardening in the steel develpements. ${ }^{1)}$ As a solution of these issues, steels containing higher carbon content than $0.2 \%$ are expected to be used. However, machinability generally becomes low with high hardness of steel depending on the carbon content. In developing steels suitable for the manufacturing processes, the effect of the carbon content should be studied to improve machinability.

Many studies have associated the machinability with the carbon content so far. Aylward ${ }^{2)}$ reported that the machinability decreased with the carbon content more than approximately $0.2 \%$ in cutting of steels with changing car-

\footnotetext{
* Corresponding author: E-mail: aiso.e88.toshiharu@jp.nipponsteel.com
}

bon content from about $0.1 \%$ to about $1.0 \%$. Arai and Shi$\mathrm{raga}^{3)}$ associated machinability with heat treatments on JIS SCM steels in carbon contents from $0.15 \%$ to $0.41 \%$. They reported that the cutting force significantly depended on hardness of the steels, and that the effect of carbon content was little when the hardness was nearly the same. Sampei et $a l^{4)}$ evaluated machinability of a bainitic microalloyed steel with approximately $0.04 \% \mathrm{C}$ and a JIS SCM435 steel with approximately $0.35 \% \mathrm{C}$ after quenching and tempering of both steels. They reported that the smaller tool wear occurred in turning of the lower carbon steel with nearly the same hardness. Hence, the other factors than the carbon content affecting machinability should be excluded to evaluate machinability as demonstrated in the actual manufacturing of gears.

Gears are generally shaped in cutting with a multipleblade cutter, called a hob. Gear cutting is a complicated machining operation involving the rotations of the hob and workpiece material with the linear motion of the hob axis. As an equivalent manner for analyzing the cutting mechanism, interrupted cutting is usually performed using a single-blade tool, called a fly tool. ${ }^{5-7)}$ The tool wear and damages depend on stress and temperature on tool face, which are induced by the cutting force. ${ }^{8)}$ In order to evaluate the cutting force, the shear deformation of the workpiece material and friction on the tool face should be studied in the three-dimensional 
cutting simulation of the gear cutting, including fly cutting. As cutting simulation approaches, an instantaneous cutting force model using the cutting coefficient, a minimum cutting energy analysis model, and finite element method have been proposed in analysis of the cutting mechanism. ${ }^{9}$ Predicting the cutting force with the chip flow direction in a relatively short computational time, the energy analysis model was applied to the general machining conducted in the machine shops such as turning ${ }^{10)}$ and milling, ${ }^{11)}$ and others.

This study discusses the effect of carbon content on machinability in fly cutting of steels with $0.2 \% \mathrm{C}, 0.4 \% \mathrm{C}$, and $0.6 \% \mathrm{C}$, which are prepared with controlling their hardness and microstructure to be nearly the same through controlling the heat treatment conditions. Then, the shear deformation of the workpiece material and the friction on the tool face are characterized in the cutting simulations based on the energy analysis model. Finally, the tool wear for the carbon contents is discussed with adhered material and delamination of the coated thin layer in the surface analysis.

\section{Experimental Procedures}

\subsection{Preparation of Workpiece Material}

The carbon content in the testing steels was adjusted in $0.2 \%, 0.4 \%$, and $0.6 \%$ with adding Mn for control of hardenability, as shown in Table 1. The steels were vacuum melted and cast into $50 \mathrm{~kg}$ ingots, which were forged into $65 \mathrm{~mm} \times 50 \mathrm{~mm}$ rectangular bars. The bars were homogenized at $1523 \mathrm{~K}$ for $60 \mathrm{~min}$ and then cooled in air. Then, the bars were held at $1173 \mathrm{~K}$ for $60 \mathrm{~min}$ and air-cooled for

Table 1. Chemical composition (mass\%), Vickers hardness (HV) and tempering condition of the work materials.

\begin{tabular}{cccccccc}
\hline & $\mathrm{C}$ & $\mathrm{Si}$ & $\mathrm{Mn}$ & $\mathrm{S}$ & $\mathrm{O}$ & Hardness & $\begin{array}{c}\text { Tempering } \\
\text { condition }\end{array}$ \\
\hline $0.2 \mathrm{C}$ & 0.20 & 0.011 & 2.00 & 0.0008 & 0.0023 & 213 & $803 \mathrm{~K} / 300 \mathrm{~min}$ \\
$0.4 \mathrm{C}$ & 0.39 & 0.013 & 1.97 & 0.0010 & 0.0015 & 214 & $903 \mathrm{~K} / 300 \mathrm{~min}$ \\
$0.6 \mathrm{C}$ & 0.60 & 0.016 & 1.96 & 0.0010 & $<0.001$ & 207 & $943 \mathrm{~K} / 300 \mathrm{~min}$ \\
\hline
\end{tabular}

normalizing. Rectangular bars measuring $54 \mathrm{~mm} \times 39 \mathrm{~mm}$ in cross-section and $330 \mathrm{~mm}$ in length were cut out from the forged bars; held at $1173 \mathrm{~K}$ for $30 \mathrm{~min}$; and water-quenched and tempered at the time and temperature shown in Table 1. The tempering temperature was changed according to the type of the testing steel to reduce the difference in hardness. The workpiece specimens measuring $50 \mathrm{~mm} \times 35 \mathrm{~mm}$ in cross-section and $70 \mathrm{~mm}$ in length were cut out from the heat-treated rectangular bars. The hardness of all steels was $210 \pm 4 \mathrm{HV}$, as shown in Table 1, and their microstructure was tempered martensite, as shown in Fig. 1. Cementite increased in size and quantity with the carbon content and the grain size was approximately $1 \mu \mathrm{m}$ in the $0.6 \% \mathrm{C}$ steel.

\subsection{Cutting Test}

The cutting tests were conducted in interrupted cutting with a fly tool on a machining center, as shown in Fig. 2(a), where the cutting conditions are shown in Table 2 . The tool material was made of high speed steel (HSS) as generally used in hob cutting. The rake and flank faces were coated with TiAlN thin layer by physical vapor deposition, where the coating thickness and surface roughness were approximately $5 \mu \mathrm{m}$ and Ra $0.2 \mu \mathrm{m}$, respectively. During cutting, the cooling air was supplied near the cutting edge. In the tests, the workpiece specimen was cut by tool rotation with a feed motion in the direction designated in Fig. 2(a). Subsequently, the pick feeds were repeated in the Z-direction with the same cutting operations. Figure 2(b) illustrates the trajectory of the cutting edge motion with rotation and feed of the tool in the $\mathrm{X}-\mathrm{Y}$ plane of the workpiece. The uncut chip thickness starts at the maximum value when the cutting edge engages the workpiece, and then gradually decreases. Figure 2(c) illustrates the cutting area in $\mathrm{Y}-\mathrm{Z}$ of the workpiece with repeating the pick feed motions. In order to realize the workpiece surface cut in the cutter path with the previous pick feed, the initial cutting finishes the surface to be machined with the same tool before cutting tests. The cutting tests, then, were conducted to measure the cutting force components $F_{x}, F_{y}$, and $F_{z}$ (as designated in Fig. 2) with a piezoelectric dynamometer in a cutting length of $0.07 \mathrm{~m}$. The chips formed in the tests were collected to a $0.2 \mathrm{C}$
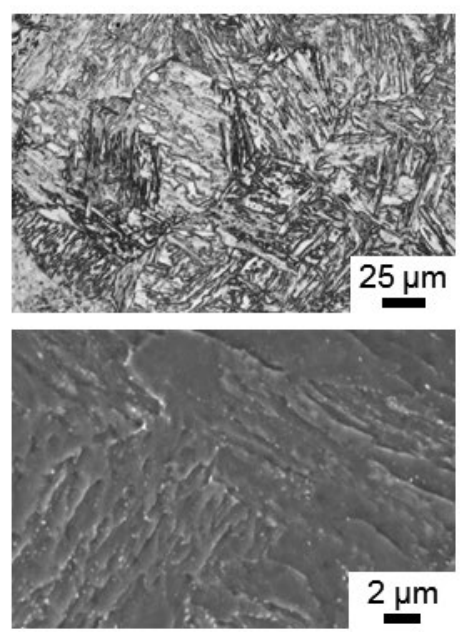

b $0.4 \mathrm{C}$
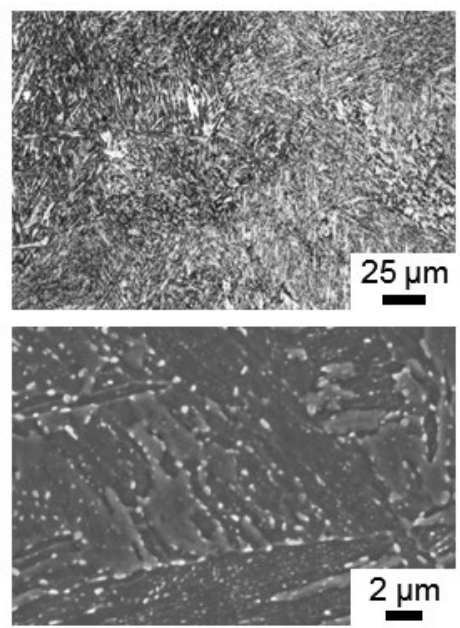

c $0.6 \mathrm{C}$

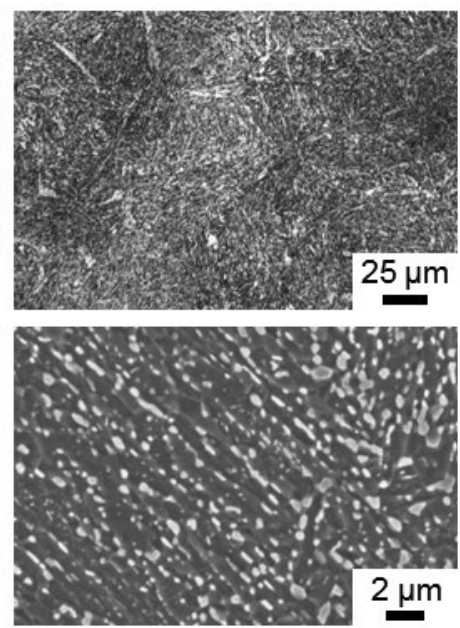

Fig. 1. Microstructure of the work materials. Optical microscope images and SEM images are shown in the upper and lower parts, respectively. 
a Test setup

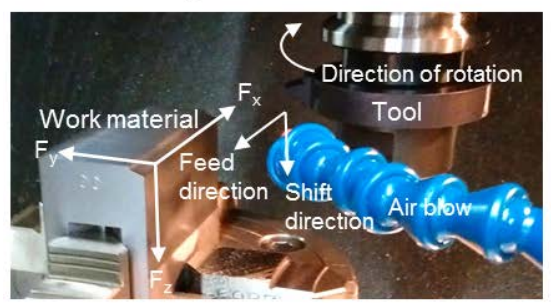

c Y-Z plane

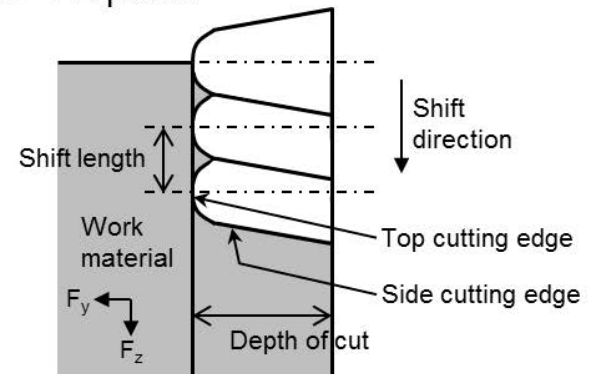

b X-Y plane

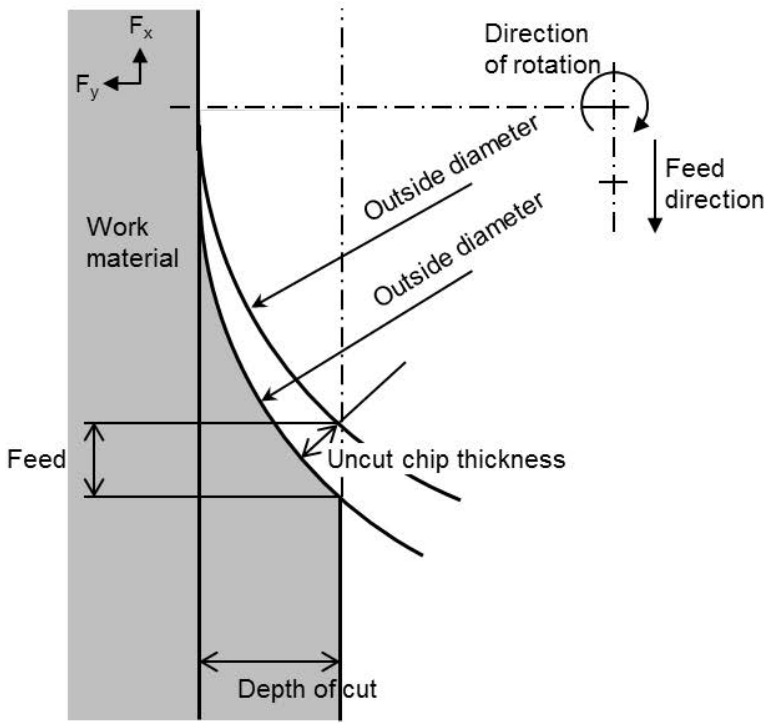

Fig. 2. (a) Setup and (b) (c) section diagrams of the gear cutting test with the fly tool. (Online version in color.)

Table 2. Cutting conditions.

\begin{tabular}{ll}
\hline Test parameter & $150 \mathrm{~m} / \mathrm{min}$ \\
Cutting speed & $0.65 \mathrm{~mm} / \mathrm{rev}$ \\
Feed rate & $4.5 \mathrm{~mm}$ \\
Depth of cut & $2.413 \mathrm{~mm}$ \\
Shift length & Air (dry) \\
Lubrication & Down cut milling \\
Cutting method & \\
\hline Tool & $90 \mathrm{~mm}$ \\
\hline Outside diameter & $0^{\circ}$ \\
Rake angle & 3 \\
Module & $20^{\circ}$ \\
Pressure angle & TiAIN coated HSS \\
\hline
\end{tabular}

observe the shapes and colors. The cutting tests were terminated at the maximum cutting length of $1.19 \mathrm{~m}$ when cracks were observed in the coated thin film of the rake face.

\subsection{Observation and Analysis of Surfaces on Chip and Tool}

The shapes and colors of the chips were observed using optical microscopy. The cross-sections were also observed after embedding the chip in resin and polishing. The hardness at the center of chip thickness, then, was measured 5 times and averaged in Vickers hardness testing at an indentation load of $1.96 \mathrm{~N}$.

The tool surfaces were observed with optical microscopy; and analyzed by scanning electron microscopy (SEM) and energy dispersive X-ray spectroscopy (EDS) with an acceleration voltage of 10 or $15 \mathrm{kV}$. The tool surfaces were sputtered by the focused ion beam (FIB) to observe the cross-sections after deposition of protective platinum (Pt) films on the tool surfaces. The cross-sections, then, were observed through SEM at a tilt angle of $52^{\circ}$. The tool specimens were also embedded in resin and polished so as to observe the cross-sections containing the chip flow directions; and then, crack formations in thin film coated on the rake faces were detected with optical microscopy. The hardness distribution in the cross-section of the tool substrate on the rake face side was also measured 5 times and averaged in the depth direction under the interface between the coated thin layer and the substrate in the Vickers hardness testing at an indentation load of $0.098 \mathrm{~N}$.

\section{Results and Discussion}

\subsection{Machinability in Terms of Cutting Mechanism}

\subsubsection{Cutting Force Model}

The fly cutting process is regarded as a milling manner with rotation and liner motion of a tool. In this study, cutting force model for milling ${ }^{11)}$ is applied to prediction of the cutting force with the chip flow direction in fly cutting. In down cutting discussed in this study, the rotation tool is fed in the direction indicated by the arrows in Fig. 3. In the chip flow model, a cutting edge is divided into the small discrete segments to define the changing edge geometry. The cutting process of the segmented edge inclined against the cutting direction is regarded as oblique cutting. Therefore, three-dimensional chip flow is interpreted as a piling up of the orthogonal cuttings in the planes containing the cutting velocities $V_{R E}$ and the chip flow velocities $V_{C}$. $V_{R E}$ in fly cutting is given by the combination of the rotation speed of the cutting edge and the feed rate of the tool axis. The orthogonal cutting model is obtained in the following formula according to Literature: ${ }^{12)}$

$$
\begin{aligned}
& \phi=\exp \left(A_{00} V+A_{01} t_{1}+A_{02} \alpha+A_{03}\right) \\
& \tau_{s}=\exp \left(A_{10} V+A_{11} t_{1}+A_{12} \alpha+A_{13}\right) \\
& \beta=\exp \left(A_{20} V+A_{21} t_{1}+A_{22} \alpha+A_{23}\right)
\end{aligned}
$$

where $\phi, \tau_{S}$ and $\beta$ are the shear angle, the shear stress on the shear plane, and the friction angle in the orthogonal cut- 


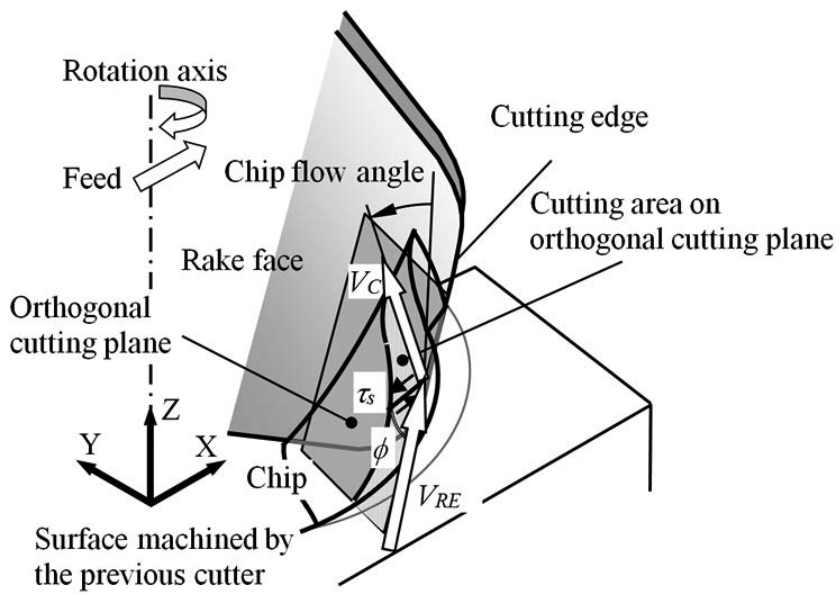

Fig. 3. Chip flow model in gear cutting test with the fly tool.

ting, respectively. $\alpha, V$, and $t_{l}$ are the rake angle, the cutting velocity, and the uncut chip thickness, respectively. The chip flow velocity $V_{C}$, in turn, is associated with $V$ :

$$
V_{c}=\frac{\sin \phi}{\cos (\phi-\alpha)} V
$$

The coefficients $A_{i j}(i=0,1,2 ; j=0,1,2,3)$ represent the sensitiveness of the cutting model to the cutting conditions and tool geometry. The workpiece and tool materials, therefore, are characterized in the coefficients. The analytical model predicts the cutting force for arbitrary cutting conditions and edge geometry using Eq. (1). Conversely, the coefficients of Eq. (1) can also be determined in the inverse analysis using the measured cutting forces.

In this study, the orthogonal cutting tests were first performed for a reference material to obtain the standard data as Eq. (1). Next, the dominant coefficients depending on the workpiece material were identified in the inverse analysis using the cutting forces actually measured in fly cutting. Subsequently, the shear angle, the shear stress on the shear plane, and the friction angle were determined for each testing steel.

\subsubsection{Identification of Orthogonal Cutting Data}

In order to identify the coefficients $A_{i j}(i=0,1,2 ; j=$ $0,1,2,3)$ in the orthogonal cutting data, the cutting tests were conducted on a lathe for a JIS S55C steel, which is the reference material with a hardness of $202 \mathrm{HV}$, almost the same hardness as that of the testing steels. The same material tools at the same rake face were employed in the orthogonal cutting tests. The dry cuttings were performed to measure the chip thickness, the principal and the thrust force components at cutting speeds of 100,120 and $150 \mathrm{~m} /$ $\mathrm{min}$ and at feed rates of $0.05,0.10,0.15,0.20$ and $0.30 \mathrm{~mm} /$ rev. The following orthogonal cutting data were obtained:

$$
\begin{aligned}
& \phi=\exp \left(0.034392 V+1885.966 t_{1}-1.302305\right) \\
& \tau_{s}=\exp \left(0.016495 V+12.05192 t_{1}+20.326468\right) \ldots .(3) \\
& \beta=\exp \left(-0.02056 V-1788.55 t_{1}-0.31449\right)
\end{aligned}
$$

The orthogonal cutting data of the $0.2 \% \mathrm{C}, 0.4 \% \mathrm{C}$, and $0.6 \% \mathrm{C}$ steels, then, were identified to compare the effect of carbon content on the cutting model using the measured cutting forces. The coefficients of Eq. (3) were applied to $A_{i j}$ $(i=0,1,2 ; j=0,1,2)$ on the assumption that the effects of the cutting conditions and the rake angle on $\phi, \tau_{S}$ and $\beta$ were similar for the testing steels. Specifically, because the rake angle of the tool was $0^{\circ}, A_{i 2}$ for the rake angle effect does not change. Moreover, as long as the same tool geometry with roundness of the edge is employed, the difference in the effect of the uncut chip thickness represented by $A_{i 1}$ is little. Under the same cutting speed, $A_{i 0}$ associated with the cutting temperature does not change so much in this study. Therefore, the effect of carbon content on these parameters is regarded as small in this study.

Based on the above discussions, $A_{i 3}(\mathrm{i}=0,1,2)$ mainly depending on the workpiece material were determined to minimize the discrepancies between the predicted and measured cutting forces. The orthogonal cutting data were obtained for the testing steels as:

(i) $0.2 \% \mathrm{C}$ steel

$$
\begin{aligned}
& \phi=\exp \left(0.034392 V+1885.966 t_{1}-1.279\right) \\
& \tau_{s}=\exp \left(0.016495 V+12.05192 t_{1}+19.86\right) \\
& \beta=\exp \left(-0.02056 V-1788.55 t_{1}-0.2927\right)
\end{aligned}
$$

(ii) $0.4 \% \mathrm{C}$ steel

$$
\begin{aligned}
& \phi=\exp \left(0.034392 V+1885.966 t_{1}-1.208\right) \\
& \tau_{s}=\exp \left(0.016495 V+12.05192 t_{1}+19.992\right) \\
& \beta=\exp \left(-0.02056 V-1788.55 t_{1}-0.34339\right)
\end{aligned}
$$

(iii) $0.6 \% \mathrm{C}$ steel

$$
\begin{aligned}
& \phi=\exp \left(0.034392 V+1885.966 t_{1}-1.183\right) \\
& \tau_{s}=\exp \left(0.016495 V+12.05192 t_{1}+20.0438\right) \\
& \beta=\exp \left(-0.02056 V-1788.55 t_{1}-0.36336\right)
\end{aligned}
$$

\subsubsection{Cutting Force Analysis and Machinability Evalua-} tion

Figure 4 compared the cutting force simulations using the orthogonal cutting data of Eqs. (4) to (6) with the actual cutting forces. Dynamic force components induced by the vibration in the cutting test system were measured in $F_{x}$ and $F_{y}$ components. When the dynamic components are excluded, the force model is validated with the identified orthogonal cutting data in agreement of the simulations with the measurements. Table 3 extracts the maximum force components from the measured cutting force values, in which the cutting force depending on the uncut chip thickness is assumed as changing along the center of vibration amplitude. According to the extractions, the cutting force components $F_{x}, F_{y}$, and $F_{z}$ increase with the carbon content. The resultant cutting force of the $0.6 \% \mathrm{C}$ steel is $11.1 \%$ larger than that of the $0.2 \% \mathrm{C}$ steel.

Figure 5 shows the shear stress on the shear plane, the shear angle, and the friction angle at the center of the cutting edge obtained in this analysis. In down cutting, the uncut chip thickness decreases with the cutter rotation after tool engagement, as shown in Fig. 2(b). Little change appears in the shear stress on the shear plane for the uncut chip thickness, as shown in Fig. 5(a). Meanwhile, as the uncut chip thickness decreases, the shear angle decreases but the friction angle increases, as shown in Figs. 5(b) and 5(c). 
a $0.2 \mathrm{C}$

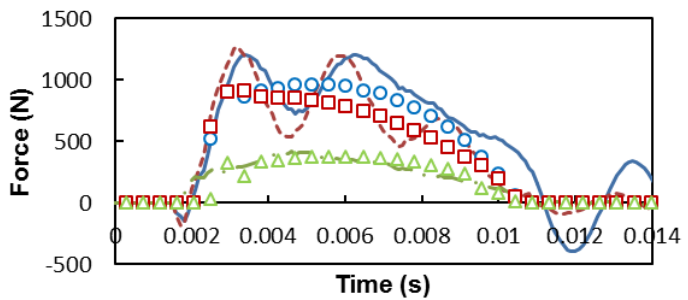

c $0.6 \mathrm{C}$

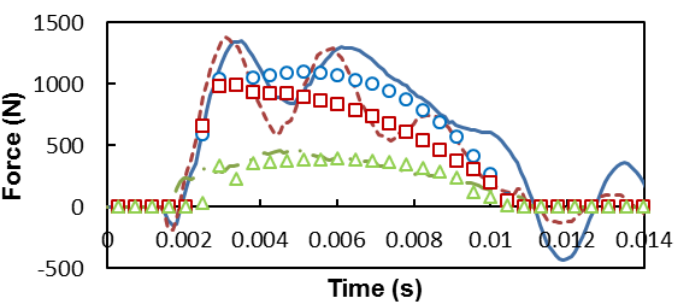

b $0.4 \mathrm{C}$

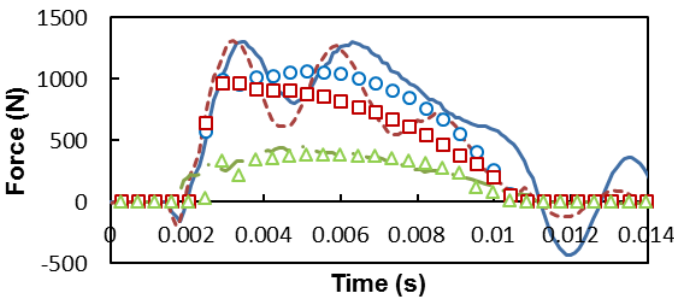

Time (s)

Fig. 4. Measured and predicted cutting forces. Measured values were obtained during a rotation of the fly tool within first $0.07 \mathrm{~m}$ cutting test. In the simulation the cutting time during a rotation and cutting edge were divided into 256 and 128 segments, respectively. (Online version in color.)

a Shear stress on shear plane

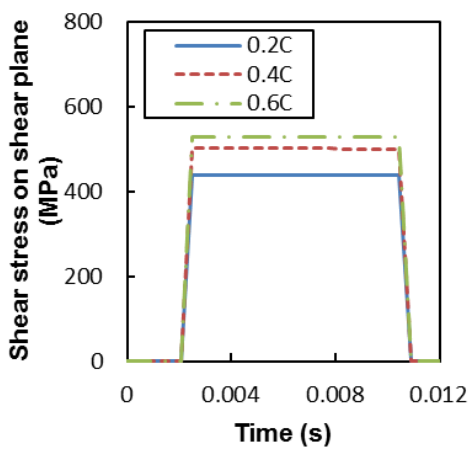

b Shear angle

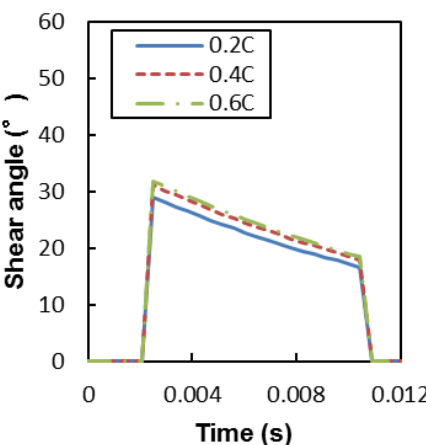

c Friction angle

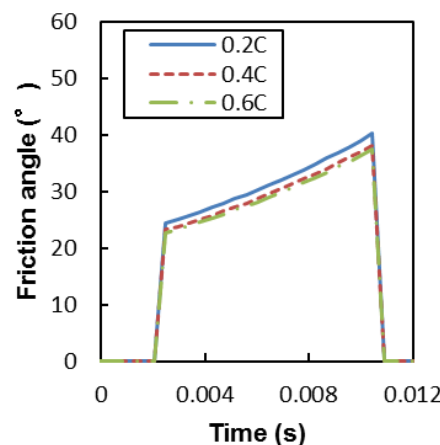

Fig. 5. Changes in the shear stress on shear plane, the shear angle and the friction angle of the orthogonal cutting model with cutting time during a rotation of the tool at a cutting area on the center of the top cutting edge. (Online version in color.)

Table 3. Maximum cutting forces from measured values in Fig. 4. The dynamic components of $F_{x}$ and $F_{y}$ are removed. The differences compared to the $0.2 \mathrm{C}$ steel are shown in brackets.

\begin{tabular}{ccccc}
\hline & $\mathrm{F}_{\mathrm{x}}[\mathrm{N}]$ & $\mathrm{F}_{\mathrm{y}}[\mathrm{N}]$ & $\mathrm{F}_{\mathrm{z}}[\mathrm{N}]$ & Resultant force $[\mathrm{N}]$ \\
\hline $0.2 \mathrm{C}$ & 962 & 908 & 423 & 1389 \\
$0.4 \mathrm{C}$ & 1054 & 963 & 452 & 1498 \\
& $(+9.6 \%)$ & $(+6.1 \%)$ & $(+6.9 \%)$ & $(+7.8 \%)$ \\
$0.6 \mathrm{C}$ & 1094 & 987 & 460 & 1544 \\
$(+13.7 \%)$ & $(+8.7 \%)$ & $(+8.7 \%)$ & $(+11.1 \%)$ \\
\hline
\end{tabular}

The changes are owing to the roundness of the cutting edge and the indentation force acting on the cutting edge, as shown in Fig. 6. When the uncut chip thickness is small, the workpiece is mainly removed at low shear angle in the area around the edge roundness at large negative rake angle. The indentation force, which is induced by the plastic flow in the region of the material separation into a chip and a generated surface, also becomes relatively large against the force of chip formation. As a result, the ratio of the thrust to the principal force increases with loading force onto the tool edge upward in a small uncut chip thickness. In this

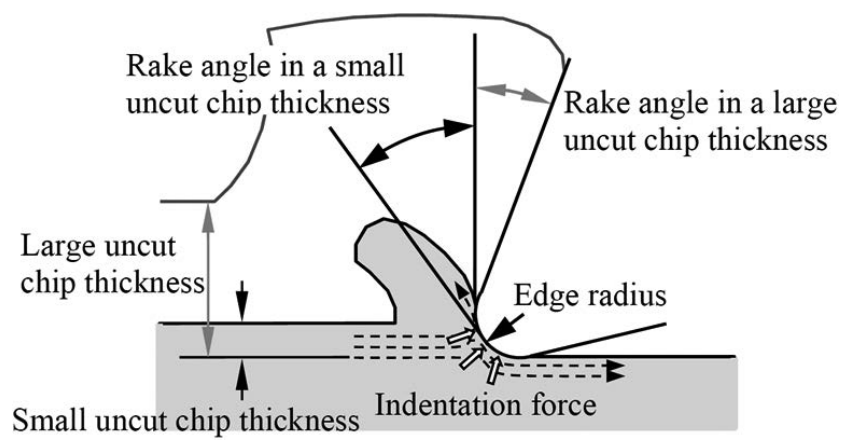

Fig. 6. Schematic illustration of a cutting process showing the effect of edge radius on cutting model.

study, such the edge effect is included in the friction angle characteristic of the orthogonal cutting data. The friction angle, therefore, becomes large in small uncut chip thicknesses. Because $A_{i j}(i=0,1,2 ; j=0,1,2)$ in Eqs. (4) to (6) refer to those of the reference material in this analysis, as described in Section 3.1.2, the sensitive parameters for the uncut chip thickness on the orthogonal cutting model do not change for the testing steels. Therefore, the shear angle, the shear stress on the shear plane, and the friction angle depend 
on the carbon content in the workpiece material.

Figure 7 shows the orthogonal cutting parameters at the maximum uncut chip thickness. Here, the shear strain $\gamma$ and the friction coefficient $\mu$ are given by the shear angle $\phi$, the friction angle $\beta$, and the rake angle $\alpha$ :

$$
\begin{gathered}
\gamma=\frac{\cos \alpha}{\sin \phi \cos (\phi-\alpha)} \\
\mu=\tan \beta \ldots \ldots \ldots . . .
\end{gathered}
$$

The shear stress on the shear plane increases with the carbon content. For example, the stress of the $0.6 \% \mathrm{C}$ steel is $20.2 \%$ higher than that of the $0.2 \% \mathrm{C}$ steel. The shear strain and friction coefficient slightly decrease with the higher carbon content. Meanwhile, the influences of the carbon content on the shear strain and friction coefficient are small. The rates of reduction in the shear strain and the friction coefficient of the $0.6 \% \mathrm{C}$ steel are $-5.5 \%$ and $-7.6 \%$ compared to those of the $0.2 \% \mathrm{C}$ steel, respectively.

The shear stress on the shear plane is associated with the hardness of the chips, as is equivalent to the deformation resistance of the materials in the primary shear zone. ${ }^{13)}$ During a rotation of the cutter, a chip is formed in simultaneous cutting on the top and the side cutting edges, as shown in Fig. 2(c). The similar chip shapes are observed in cutting of all testing steels, as shown in Fig. 8. In terms of the temper color, the chip of the $0.2 \% \mathrm{C}$ steel is brownish. Meanwhile, the chips of the $0.4 \% \mathrm{C}$ and $0.6 \% \mathrm{C}$ steels are colored by uniformly light blue, which indicates the high cutting temperatures under the large cutting forces of steels with high carbon contents. In microstructures of the chips shown in Fig. 9, plastic flows are observed along the shear direction for the chip formation from the upper right to the lower left in the pictures. The hardness in the cross-sections of the chips shown in each picture of Fig. 9 increases with the carbon content. Figure $\mathbf{1 0}$ shows a good correlation between the shear stress on the shear plane in Fig. 7(a) and the hardness of the chips in Fig. 9. Because the hardness of testing steels is nearly the same each other, the difference in the shear stress on the shear plane is owing to the work

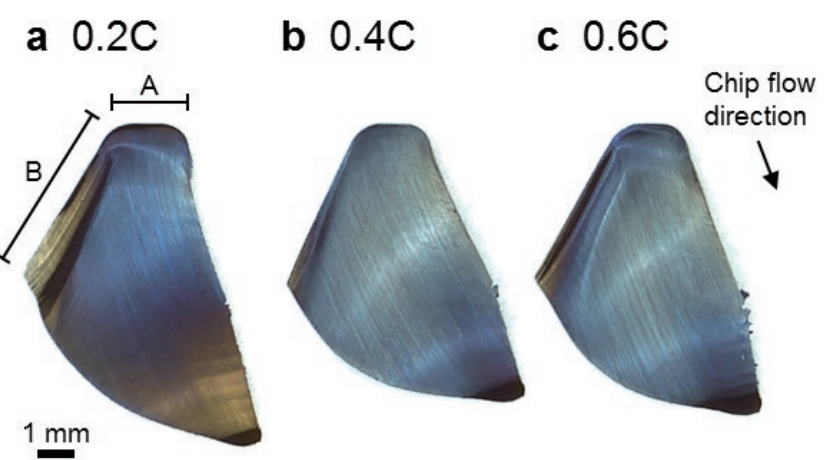

Fig. 8. Representative chips collected during first $0.07 \mathrm{~m}$ cutting tests. The contact surfaces with the tool are observed. The lines A and B indicate the parts of the chip formed by top cutting edge and side cutting edge, respectively.

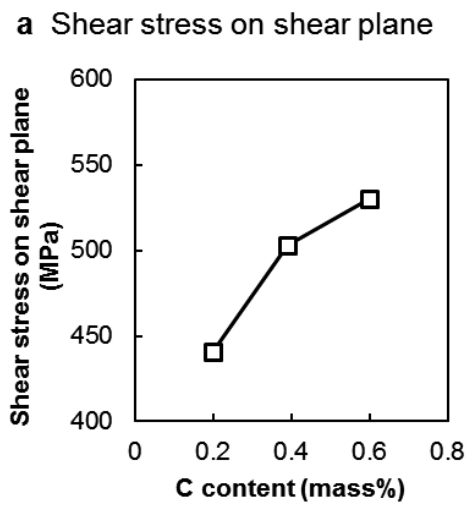

b Shear strain

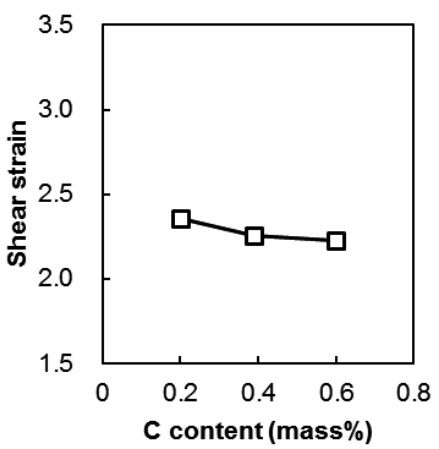

c Mean coefficient of friction

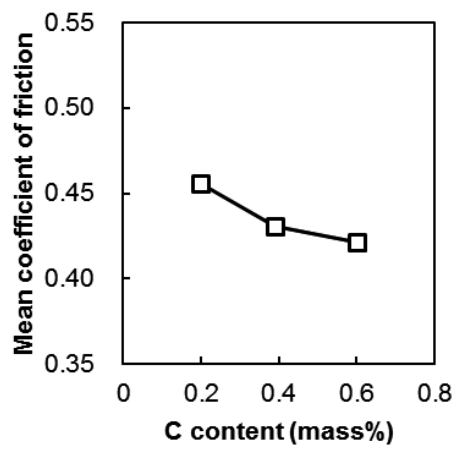

Fig. 7. Changes in the shear stress on shear plane, the shear strain and the mean friction coefficient of the orthogonal cutting model with carbon contents in the steels, at an early time of cutting when the uncut chip thickness becomes maximum in Fig. 5 .

a $0.2 \mathrm{C}$

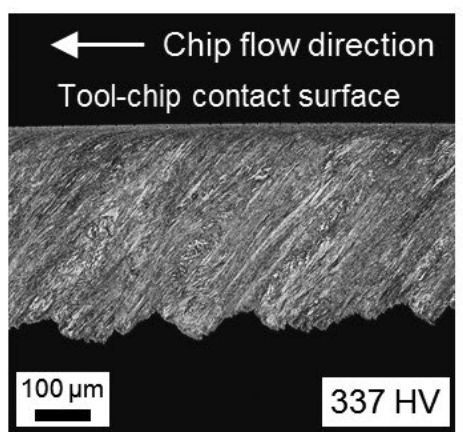

b $0.4 \mathrm{C}$



\section{c $0.6 \mathrm{C}$}

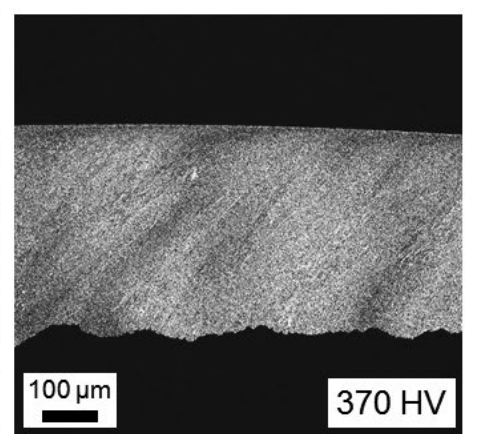

Fig. 9. Optical microscope images and hardness of the cross-section of the chips collected during first $0.07 \mathrm{~m}$ cutting tests. The hardness measurement was performed around the center position in the chip thickness using a load of $1.96 \mathrm{~N}$. 
hardening of the workpiece material during chip formation. According to Literature, ${ }^{14)}$ the work hardening rate increases with the volume fraction of cementite in static tensile tests. Meanwhile, plastic deformations occur in the chip formation at high temperatures, high speeds and large strains. Although the deformation modes are different between the static tensile and the chip formation, a large volume fraction of cementite with a high carbon content, as shown in Fig. 1 , promotes the work hardening during chip formation with increasing the shear stress on the shear plane.

\subsection{Machinability in Terms of Tool Damage}

\subsubsection{Surface Appearance of the Tools}

Because the top and side cutting edges remove the workpiece simultaneously in fly cutting, the chips flow on the rake face at an inclination angle with respect to the top cutting edge, as designated by the arrow in Fig. 11. The cracks are observed on the coated thin film on the rake faces after cutting of all testing steels. The cracks were generated in nearly vertical direction to the chip flow. The cracking occurred at a cutting length of $1.19 \mathrm{~m}$ in cutting of the $0.2 \% \mathrm{C}$ and $0.4 \% \mathrm{C}$ steels but at a shorter cutting length of $0.84 \mathrm{~m}$ for the $0.6 \% \mathrm{C}$ steel. The tool wears on the cutting edge with the $0.2 \% \mathrm{C}$ and $0.4 \% \mathrm{C}$ steels are relatively small in view from the flank face, while the large wear is observed clearly on the cutting edge with the $0.6 \% \mathrm{C}$ steel.

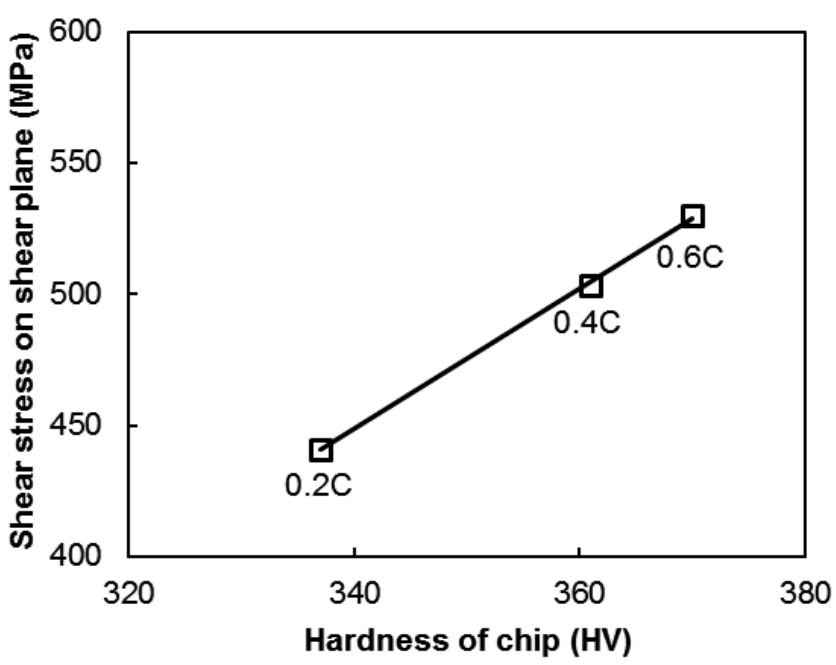

Fig. 10. Relationship between the shear stress on shear plane and the hardness of chips, obtained from Figs. 7(a) and 9.

\subsubsection{Tool Damage on the Rake Faces of the Tools}

In the EDS maps of Fig. 12, the tool coating components, $\mathrm{Ti}$ and $\mathrm{Al}$, are detected on the overall rake faces. Adhesions of all testing steels are confirmed by the bright contrasts in the backscattered electron images (BEI). Mn and $\mathrm{O}$, which are associated with oxides mainly composed of $\mathrm{Mn}$ formed during cutting, are also detected in the same regions. The regions of the adhered workpiece materials, which are regarded as the tool-chip contact area, are nearly the same for all testing steels though adhesions occur locally. The friction force depends on the tool-chip contact area and the shear strength around the interface between the tool and the chip. Therefore, the friction force does not change so much for all testing steels. The friction coefficients are actually different little for the carbon contents, as shown in Fig. 7(c). The analysis for the effects of carbon content on the friction coefficient agrees well with observation.

After etching of the cross-sections of the tools in nital, dark-contrasted regions in the maximum depth of approximately $30 \mu \mathrm{m}$ were observed in the tool substrates on the rake face sides, as shown in Fig. 13(a). Cracks in the coated thin film are observed around this region. As evident from the cross-sectional micrograph of Fig. 13(b), the cracks propagated through the coated thin film, and the HSS substrate was plastically deformed and raised around the through cracks. Because the coating thickness of about $5 \mu \mathrm{m}$ in this region is nearly the same as the original thickness, the wear of the coated layer is regarded as little. According to the hardness distribution of the HSS substrate in Fig. 14, the hardness is reduced to approximately $600 \mathrm{HV}$ in the cracking region.

The thermal softening and plastic deformation of the HSS substrate in Figs. 13 and 14 suggest that the temperature rise on the rake face during cutting achieves higher than $873 \mathrm{~K}$, at which HSS starts the temper softening. Meanwhile, the hard and brittle coating material does not follow the plastic deformation of the substrate. As a result, the crack initiation and propagation occur in the coated thin film. Such the cracking mechanism in the coated layer has been reported in the actual hobbing and in the friction tests simulating hobbing. ${ }^{15,16)}$ Based on the increase in the cutting force and the change of high-temperature temper color of the chip with the carbon content, as discussion referred to Table 3 and Fig. 8, the higher heat generation in cutting of the $0.6 \% \mathrm{C}$ steel resulted in the rapid cracking of the coated layer at a shorter cutting length by the abovementioned mechanism. a $0.2 \mathrm{C}$

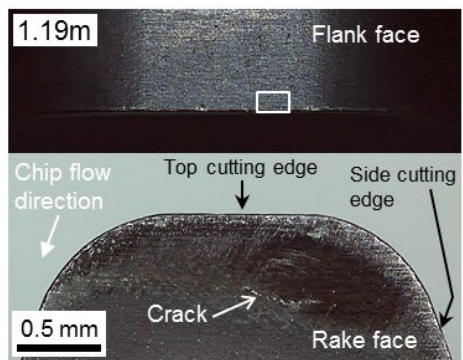

b $0.4 \mathrm{C}$

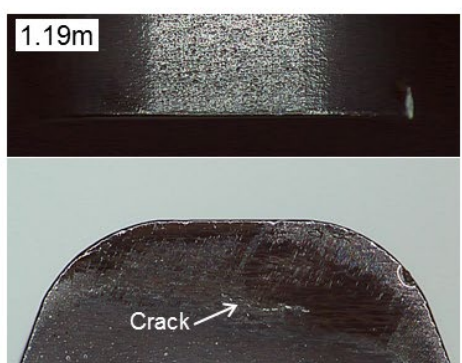

c $0.6 \mathrm{C}$



Fig. 11. Optical microscope images of the rake faces and the flank faces of the tools after cutting (a) the $0.2 \mathrm{C}$ steel, (b) the $0.4 \mathrm{C}$ steel and (c) the $0.6 \mathrm{C}$ steel. The areas within the rectangles on the flank faces of (a) and (c) are magnified in the backscattered electron images of Fig. 15. (Online version in color.) 
a $0.2 \mathrm{C}($ after $1.19 \mathrm{~m})$
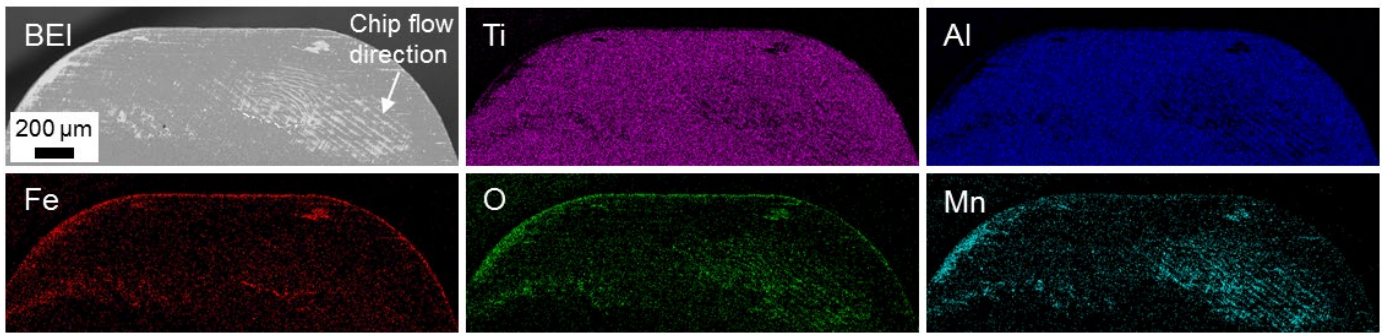

b $0.4 \mathrm{C}$ (after $1.19 \mathrm{~m}$ )
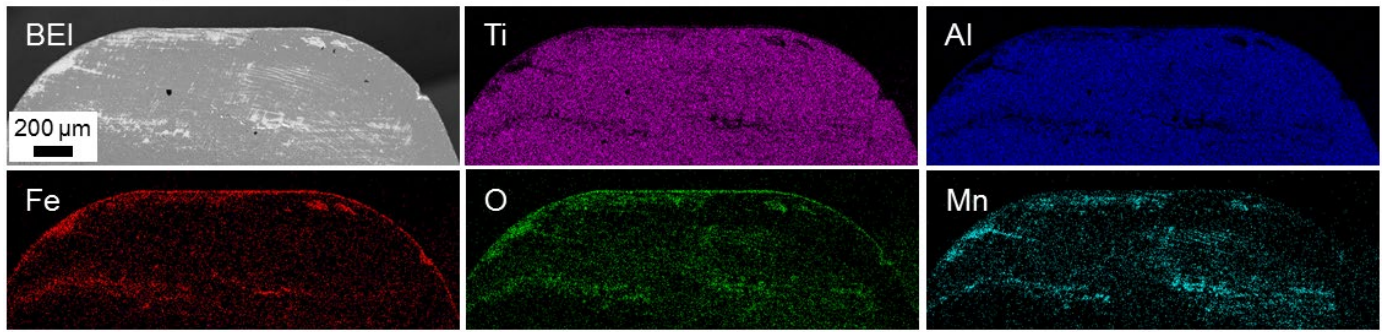

\section{c $0.6 \mathrm{C}$ (after $0.84 \mathrm{~m}$ )}
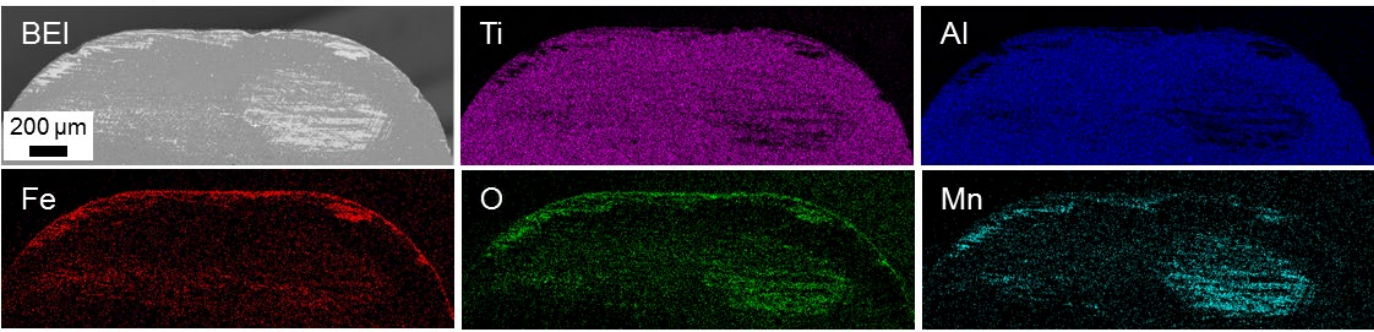

Fig. 12. Backscattered electron images (BEI) and EDS maps of the rake faces after cutting. The electron beam acceleration voltage was $15 \mathrm{kV}$. (Online version in color.)

a

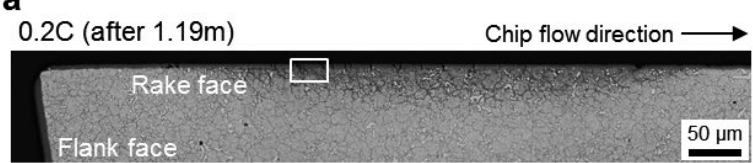

$0.4 \mathrm{C}($ after $1.19 \mathrm{~m})$

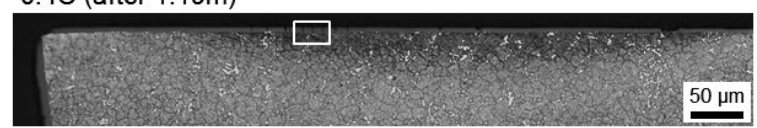

$0.6 \mathrm{C}$ (after $0.84 \mathrm{~m})$

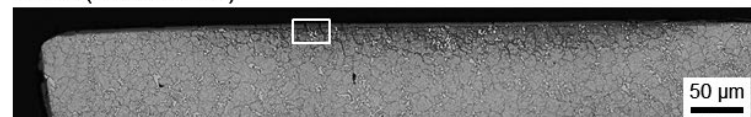

b
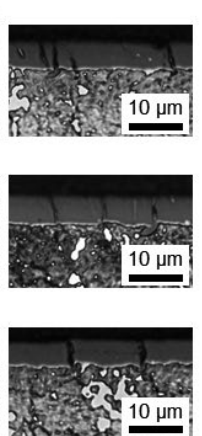

$0.6 \mathrm{C}$ (after $0.84 \mathrm{~m}$ )

$\longleftarrow$ Chip flow direction

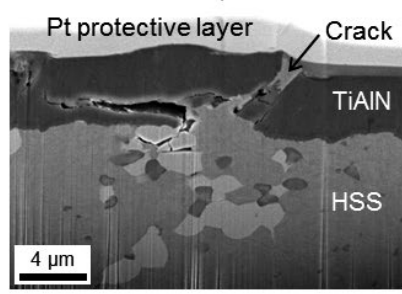

Fig. 13. (a) Optical microscope images of polished cross-sections of the tools after cutting the $0.2 \mathrm{C}$ steel, the $0.4 \mathrm{C}$ steel and the $0.6 \mathrm{C}$ steel. The cross-sections were etched with nital. Overview images are shown in the left and the areas in the rectangles are magnified in the right. (b) An SEM image of a FIB cross-section made on the rake face of the tool after cutting the $0.6 \mathrm{C}$ steel. The electron beam acceleration voltage was $10 \mathrm{kV}$.

\subsubsection{Tool Damage on the Flank Faces of the Tools}

As shown in Fig. 15(a), the relatively uniform width of flank wear land is observed in approximately $30 \mu \mathrm{m}$ in cutting of the $0.2 \% \mathrm{C}$ steel. In contrast, the wear in cutting of the $0.6 \% \mathrm{C}$ steel is larger despite shorter cutting length in the test. Two worn regions are defined here: one with a uniform wear width of approximately $37 \mu \mathrm{m}$, and the other with a non-uniform wear width of a maximum of approximately $94 \mu \mathrm{m}$, as designated by $V B$ and $V B_{\max }$ in Fig. 15(b), respectively. Near the worn cutting edges, adhered material indicated in the gray-contrasted regions is observed for both the $0.2 \% \mathrm{C}$ and $0.6 \% \mathrm{C}$ steels. The EDS analysis detects $\mathrm{Fe}$,
$\mathrm{Mn}$ and $\mathrm{O}$ in the gray regions, suggesting that the adhered material is an oxide containing $\mathrm{Fe}$ and $\mathrm{Mn}$. In the large wear region for the $0.6 \% \mathrm{C}$ steel, the adhered material is widely detected. Furthermore, the delamination of coated thin layer occurs with exposing the HSS substrate, as shown in the bright-contrasted regions.

Figure 16(a) shows the cross-section of an unused tool with thin coated layer on the cutting edge. The coated layer became thinner in the uniform worn regions, as shown in Figs. 16(b) and 16(c). The wear progress shaped concave areas on the coating surface, as indicated by the arrows in Figs. 16(b) and 16(c); and the adhered materials accu- 
mulated in the areas. According to the cross-section of the severe worn region shown in Fig. 16(d), the wear progress promoted delamination of the coated layer to expose the substrate.

In cutting of the $0.6 \% \mathrm{C}$ steel, the wear initially develops near the cutting edge and suddenly increases with severe adhesion when the delamination of the coated layer partly occurs. The tool wear mechanism before exposing the substrate is classified into abrasive wear controlled by the mechanical behavior and adhesive and/or diffusion wears as thermal sensitive manner. Abrasive wear is mainly induced in ploughing by hard inclusions in steels. As the total oxygen content of steel increases, hard oxide inclusions such

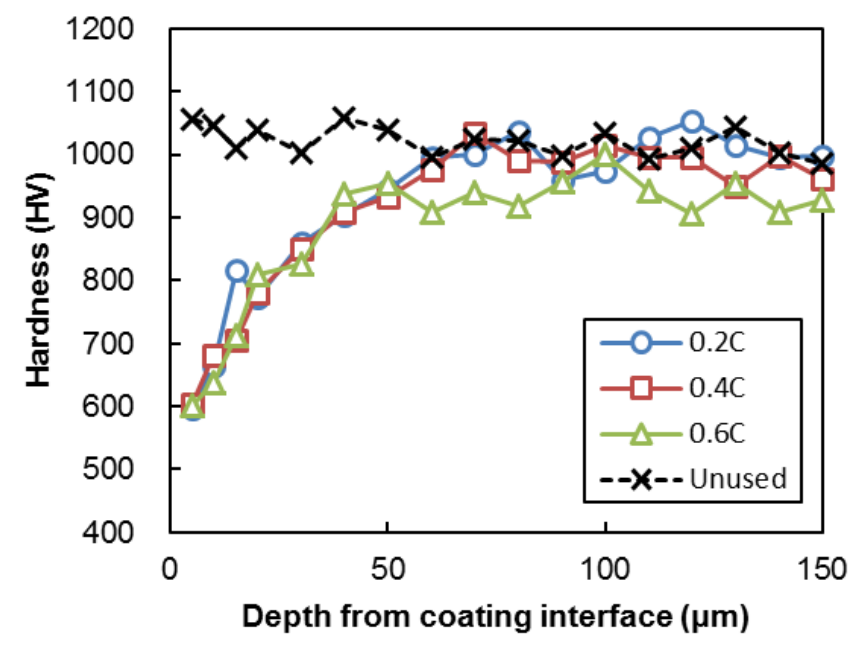

Fig. 14. Hardness distribution of the HSS substrate of the rake face as a function of the depth from the coating/substrate interface. The curves are shown for an unused tool and the tools after cutting the $0.2 \mathrm{C}$ steel for $1.19 \mathrm{~m}$, the $0.4 \mathrm{C}$ steel for $1.19 \mathrm{~m}$ and the $0.6 \mathrm{C}$ steel for $0.84 \mathrm{~m}$. The measurement was performed around the position where a thickness of dark etching area was maximum, showing in the left images in Fig. 13(a). (Online version in color.)

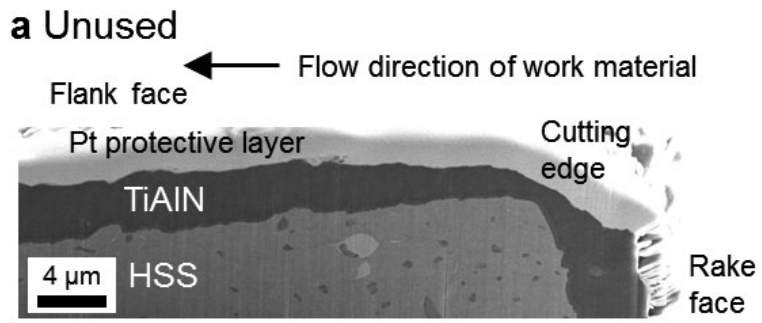

\section{b $0.6 \mathrm{C}, \mathrm{A}-\mathrm{B}$ cross-section}

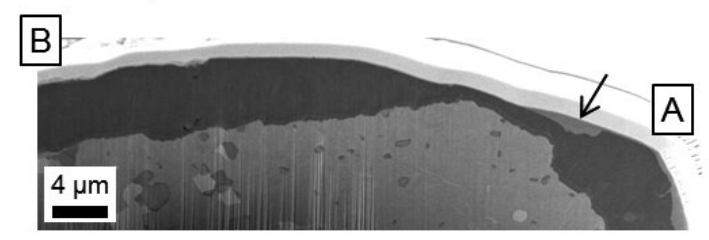

\section{c $0.6 \mathrm{C}, \mathrm{C}-\mathrm{D}$ cross-section}

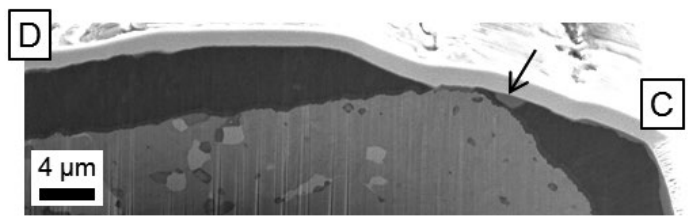

\section{d $0.6 \mathrm{C}, \mathrm{E}-\mathrm{F}$ cross-section}

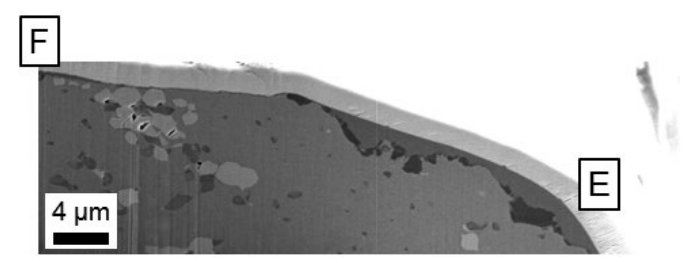

Fig. 16. SEM images of FIB cross-sections of (a) an unused tool and $(\mathrm{b}-\mathrm{d})$ the tool after cutting the $0.6 \mathrm{C}$ steel for $0.84 \mathrm{~m}$ The cross-sections in (b), (c) and (d) were obtained at the positions of the three lines in Fig. 15(b), i.e. between A and $\mathrm{B}$, between $\mathrm{C}$ and $\mathrm{D}$ and between $\mathrm{E}$ and $\mathrm{F}$. The crosssection in (a) was obtained at the position corresponding to them. Arrows in (b) and (c) indicate adhered material attached to the worn coating surface. The electron beam acceleration voltage was $10 \mathrm{kV}$.

\section{a $0.2 \mathrm{C}($ after $1.19 \mathrm{~m})$}

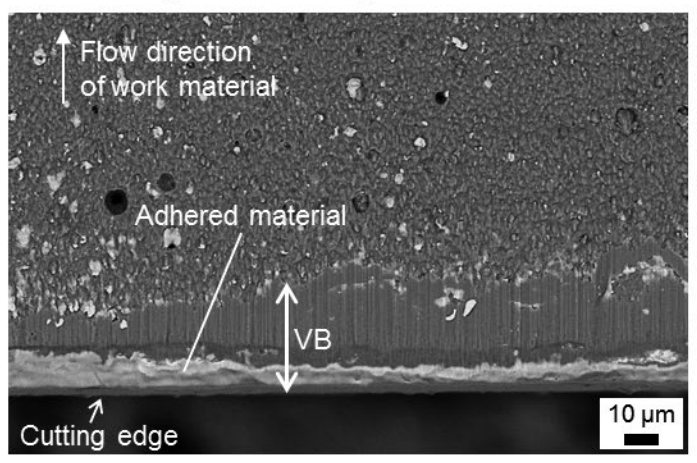

\section{b $0.6 \mathrm{C}$ (after $0.84 \mathrm{~m})$}
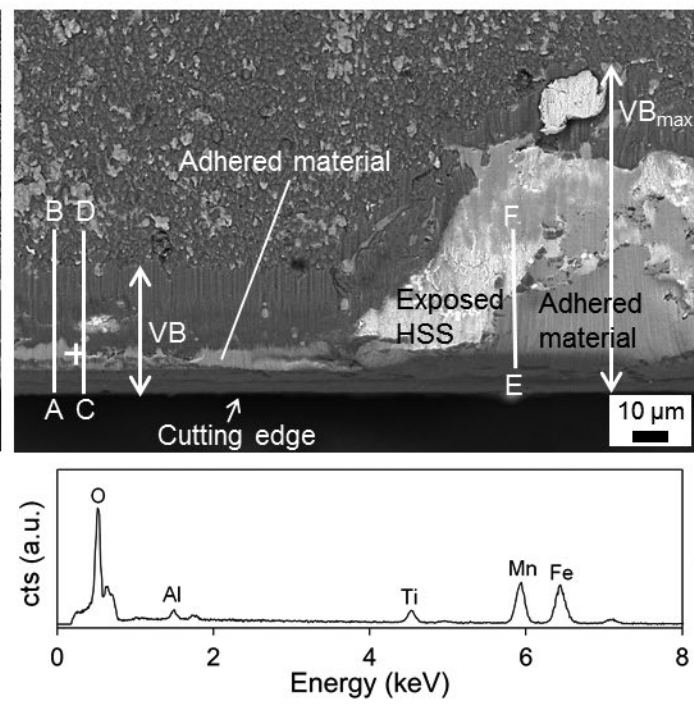

Fig. 15. Backscattered electron images and an EDS spectrum on the flank faces of the tools after cutting (a) the $0.2 \mathrm{C}$ steel and (b) the $0.6 \mathrm{C}$ steel. The images in (a) and (b) correspond to the rectangles in the flank faces of Figs. 11(a) and 11(c). The EDS spectrum was obtained at the position indicated by the cross in the image of (b). The lines between $\mathrm{A}$ and $\mathrm{B}$, between $\mathrm{C}$ and $\mathrm{D}$ and between $\mathrm{E}$ and $\mathrm{F}$ indicate the positions of the cross-sections in Fig. 16. The electron beam acceleration voltage was $15 \mathrm{kV}$. 
as alumina increase in quantity. However, the $0.6 \% \mathrm{C}$ steel includes the lowest total oxygen content among the testing steels, as shown in Table 1. Hence, the effect of carbon content on flank wear cannot be explained in terms of the hard oxide inclusions. As another factor, the $0.6 \% \mathrm{C}$ steel includes the highest cementite amount among the testing steels. However, the hardness of cementite less than about $13 \mathrm{GPa}^{17)}$ is lower than that of the coated thin film with general hardness of $20 \mathrm{GPa}$ or higher. In addition, the size of cementite was small, i.e., less than about $1 \mu \mathrm{m}$, as shown in Fig. 1. Based on the discussions, the cementite presumably contributed little to abrasive wear. Therefore, abrasive effect is minor in flank wear in the testing steels. Consequently, thermal wear may become dominant in the flank wear progress for the $0.6 \% \mathrm{C}$ steel with a large cutting force at high cutting temperatures. The adhered material was discovered in the concave portions created by wear on the coating surface, as indicated by the arrows in Figs. 16(b) and 16(c). This suggests the following adhesive wear process: the parts of the coating material are removed together with the adhered material and subsequently transported away in the chip flow. Such an intense adhesive wear mainly promotes the flank wear progress in cutting of the $0.6 \% \mathrm{C}$ steel.

\section{Conclusions}

This study discusses the effect of the carbon content on machinability in fly cutting of steels containing $0.2 \% \mathrm{C}$, $0.4 \% \mathrm{C}$, and $0.6 \% \mathrm{C}$, as demonstration of gear machining. In preparation of the workpiece materials, the tempering temperature after quenching was adjusted to achieve the similar hardness of approximately $210 \mathrm{HV}$ and to create a tempered martensite microstructure. The effect of the carbon content has been discussed in terms of the cutting simulation in the energy force model with identifying the orthogonal cutting data. The results of this study are summarized as follows:

(1) Cutting force

The cutting force increases with the carbon content affecting the shear stress on the shear plane. The shear stress on the shear plane is associated well with the work hardening during chip formation, where the work hardening increases with volume fraction of cementite depending on the carbon content.

(2) Tool damage

Crack initiation and propagation occur in the coated thin film on the rake face for all testing steels because the coating material does not follow deformation of the HSS substrate under thermal softening and plastic deformation. In cutting of the $0.6 \% \mathrm{C}$ steel with the larger cutting force and higher cutting temperature, cracking in the coated thin film occurs in a cutting length shorter than those for the $0.2 \% \mathrm{C}$ and $0.4 \% \mathrm{C}$ steels.

The flank wear is small in cutting of the $0.2 \% \mathrm{C}$ and $0.4 \% \mathrm{C}$ steels, while a larger flank wear develops in cutting of the $0.6 \% \mathrm{C}$ steel due to delamination of coated thin layer with the tool substrate exposure. The large wear in cutting of the $0.6 \% \mathrm{C}$ steel is mainly induced by thermal wear with adhesion at high cutting temperatures.

\section{REFERENCES}

1) O. Furukimi, K. Kobayashi, T. Ochi, T. Tsuchiyama and G. Miyamoto: Netsu Shori (J. Jpn. Soc. Heat Treat.), 50 (2010), 99 (in Japanese).

2) P. T. Aylward: SAE Technical Paper, No. 730113, Society of Automotive Engineers, New York, (1973), 1.

3) M. Arai and T. Shiraga: J. Jpn. Soc. Precis. Eng., 63 (1997), 438 (in Japanese).

4) T. Sampei, T. Shiraga, K. Matsumoto, S. Ishizaki, H. Kido and T. Hosoda: NKK Giho, 129 (1989), 23 (in Japanese).

5) H. Matsuoka and Y. Tsuda: Trans. Jpn. Soc. Mech. Eng. C, 66 (2000), 2038 (in Japanse).

6) K. Miyazaki, H. Yoshimura, T. Ono and M. Nakamura: Toyota Tech. Rev., 52 (2002), 78 (in Japanese).

7) Y. Umezaki, Y. Funaki, S. Kurokawa, O. Ohnishi and T. Doi: J. Adv. Mech. Des. Syst. Manuf., 6 (2012), 206.

8) T. Matsumura: Bull. Iron Steel Inst. Jpn., 22 (2017), 81 (in Japanese).

9) T. Matsumura: J. Jpn. Soc. Precis. Eng., 80 (2014), 803 (in Japanese).

10) E. Usui, A. Hirota and M. Masuko: J. Eng. Ind., 100 (1978), 229.

11) T. Matsumura and E. Usui: Int. J. Mach. Tool. Manuf., 50 (2010), 458.

12) Y. Kashimura: J. Jpn. Soc. Precis. Eng., 51 (1985), 2115 (in Japanese).

13) K. Nakayama and K. Tamura: J. Jpn. Soc. Precis. Eng., 29 (1963), 649 (in Japanese).

14) A. Ohmori, S. Torizuka and K. Nagai: ISIJ Int., 44 (2004), 1063.

15) S. Hogmark and M. Olsson: SME Technical Paper, Society of Manufacturing Engineers, Dearborn, Michigan, (2005), 1.

16) T. Aiso, U. Wiklund, M. Kubota and S. Jacobson: Tribol. Int., 101 (2016), 414.

17) M. Umemoto and K. Tsuchiya: Tetsu-to-Hagané, 88 (2002), 117 (in Japanese). 